\title{
A IGREJA E O NOBILIÁRIO BRASILEIRO.
}

A nobreza do Império do Brasil - iniciada com o título de Barão da Tôrre de Garcia de Ávila, conferido por Sua Majestade Imperial o Sr. $D$. Pedro $I$, no dia mesmo de sua coroação, a $\mathrm{Co}$ ronel Antônio Joaquim Pires de Carvalho e Albuquerque, "senhot da Tôrre" - teve representantes no alto clero brasileiro, que merecem ser relembrados, porque eram vultos de eleição, que dignificaram a Igreja e prestaram à Pátria e ao Império serviços de alta valia.

O Sr. D. Pedro $I I$, educado pelo virtuoso Bispo de Crisópolis, era católico convicto e nos princípios de nossa Santa Religião criou suas filhas e netos, em que pese a opinião de historiadores de que sua crença era "limitada". Encanta o entusiasmo cristão do ínclito monarca em notas que apôs à margem do "Les Origines" (1883) de Edmond de Pressensé, onde trata do Padre Nosso: "Com que fervor o repeti, quando me detive nos lugares onde Jesus Cristo o ensinou a seus apóstolos".

E durante seu grande reinado, que tanto engrandeceu a Pátria, conferiu nosso segundo Imperador foros de nobreza a sete prelados brasileiros, sendo que quatro dêsses títulos foram por êle assinados e três levaram a rubrica de sua digníssima filha, Regente do Império, Senhora Princesa Dona Isabel, Condessa d'Eu, merecendo o imperial consenso.

São, pois, os seguintes os Príncipes da Igreja Católica, que fizeram parte da Nobreza Imperial Brasileira:

Conde de Irajá - D. Manuel do Monte Rodrigues de Araújo. Nascido em 17 de março de 1796, na freguesia de Boa Vista (Recife, Capitania de Pernambuco) e falecido em 11 de junho de 1863, no Paço da Conceição, no Rio de Janeiro, era filho de João Rodrigues de Araújo e de Dona Catarina Ferreira de Araújo.

Destinado, por vontade paterna, à vida eclesiástica, teve sua educação entregue aos padres carmelitas da Congregação do Oratório, após ter, em Recife, concluído os primeiros estudos. Ali concluiu em 1817 o curso de Filosofia Racional e Moral e o de Matemática. Nesse ano irrompia a malograda rebelião contra o Go- 
vernador e Capitão-General de Pernambuco Caetano Pinto de $\mathrm{Mi}$ randa Montenegro. O jovem religioso recolheu-se, então, ao Seminário de Olinda, onde passou a freqüentar o Curso de Teologia. Concluindo-o, passou a reger a cadeira de Moral, de que, em 1822, se tornava proprietário. Também nesse ano obteve sua urdenação de presbítero.

Começando a militar na política, para a qual entretanto nunca teve grandes pendores, foi escolhido por sua província natal para ter assento na Assembléia Geral Legislativa de 1834 a 1841 e pela do Rio de Janeiro de 1845 a 1847.

Foi o 9. Bispo do Rio de Janeiro, nomeado em 1840 e confirmado por bula de S. S. o Papa Gregório XVI, cargo que honraria como poucos e onde viria a falecer.

Assinada a paz de Poncho Verde, que pôs têrmo à Revolução dos Farrapos, acompanhou Suas Majestades Imperiais em sua visita ao Rio Grande do Sul.

Capelão-mor da Família Imperial, sagrou e deu a bênção nupcial a SS. MM. II. e às princesas $D$. Januária e $D$. Francisca e batizou os Príncipes Imperiais.

Foi prelado doméstico e assistente do Sólio Pontifício. O Instituto Histórico e Geográfico Brasilerio e a Academia de Ciências e Artes de Roma o receberam como sócio efetivo.

Recebeu do Império do Brasil a Grande-Dignitária da Ordem. da Rosa, além das ordens estrangeiras de São Januário e Francisco I das Duas Sicílias, no grau de Cavaleiro.

Foi autor de vários trabalhos, entre êles um "Compêndio de Teologia Moral" e "Elementos de Direito Canônico".

Em 25 de março de 1845 o Sr. D. Pedro II conferiu-lhe o título nobiliárquico de Conde de Irajá.

No Cartório da Nobreza ficou registrado seu escudo de armas, assim descrito: um escudo com as armas dos Araújos, que são: em campo de prata uma aspa azul, carregada de cinco besantes de ouro; sôbre o escudo, à dextra uma mitra de bispo, à sinistra o báculo episcopal com a curva para fora e ao centro uma cruz de ouro florida; a corôa de conde sôbre o chapéu semi-pontifical de bispo.

Marquês de Santa-Cruz - D. Romualdo Antônio de Seixas. Nascido em 7 de fevereiro de 1787 em Cametá (Capitania do Estado do Grão-Pará e Rio Negro) e falecido em 29 de dezembro de 1860, na cidade de São Salvador (Província da Bahia), era fitho de Francisco Justiniano de Seixas e de Dona Ângela de Souza Bittencourt Seixas, e sobrinho de D. Romualdo de Souza Coelho, 8. ${ }^{\circ}$ Bispo do Pará. 
Concluídos seus primeiros estudos em Belém, seu tio fê-lo seguir para a côrte, onde freqüentou, no Convento de São Felipe Neri, da Congregação do Oratório, o curso regular, que terminou com brilhantismo. Regressou ao Brasil, com 18 anos de idade e aqui se iniciou nos estudos teológicos, concluindo-os com não menor brilhantismo. Ocupou, logo depois, no Seminário do Pará, as cadeiras de Retórica e Poética, Filosofia Racional e Moral, Teologia Dogmática, Língua Francesa e Gramática Latina. Aos dezenove anos, com a primeira tonsura, foi nomeado mestre de cerimônias do sólio.

Em 1808 foi escolhido pelo Bispo D. Manuel de Almeida de Carvalho, Governador da Capitania, para ir cumprimentar no Rio de Janeiro, em nome de sua diocese, a Família Real, que transmigrara para o Brasil e essa incumbência a soube desempenhar com tal brilhantismo que foi agraciado com o título de Cônego da Sé do Pará e condecorado com a venera de cavaleiro da Ordem de Cristo.

Regressando ao Pará em 1817, foi nomeado vigário de Cametá e capitular, durante a ausência de seu tio e arcediago.

Com 21 anos tomava ordens de subdiácono e estreava na tribuna sagrada, com o penegírico de Santo Tomás de Aquino.

Em $1 .^{\circ}$ de janeiro de 1821 foi nomeado presidente da Junta Provisória do Grão-Pará, aclamada pelo povo e pelo exército, onde obteve que os brasileiros que contra ela haviam combatido não fôssem fuzilados, para serem julgados por tribunais legítimos.

Por Decreto de 12 de outubro de 1826, foi nomeado décimo sétimo Arcebispo da Bahia.

No mesmo ano, foi eleito deputado à Assembléia Geral Legislativa, pela Província do Pará e, depois, pela da Bahia. Em 1828 foi escolhido para a Presidência da Câmara dos Deputados.

Por bula de S.S. o Para Leão XII foi designado para prelado primaz e metropolitano da Igreja Brasileira.

Em 18 de julho de 1841, como arcebispo metropolitano e Primaz do Brasil, presidiu à suntuosa solenidade da coroação e sagração do Sr. D. Pedro II, como Imperador Constitucional e Defensor Perpétuo do Brasil. Recebeu, durante êsses festejos, a insígnia da Grande Dignitária da Ordem da Rosa e a Grã-Cruz da Ordem Imperial do Cruzeiro.

Nomeado Ministro da pasta do Império, declinou modestamente dessa alta honraria, embora tôdas as insistências que the fizeram os outros membros do Conselho de Estado.

O Marquês de Santa Cruz foi uma das glórias mais legítimas da Igreja nacional. "Já grande pela ilustração - como disse Joa- 
quim Manuel de Macedo - era dotado de excessiva modéstia, de trato ameníssimo, de bondade evangélica, de tôdas as qualidades enfim, que exaltam e fazem veneranda e amável a criatura humana.

Era do Conselho de Sua Majestade, sócio do Instituto Histórico e Geográfico Brasileiro, do Instituto da África de Paris e: outras associações científicas e literárias.

$\mathrm{Na}$ Biblioteca Pública do Estado da Bahia existe expressiva tela a óleo representando o ilustre e nobre prelado, mandado confeccionar por lei provincial.

Deixou um volume de Sermões, um Diário de Vaigem do Rio de Janeiro ao Pará, e uma Memória relativa à naturalidade do Padre Antônio Vieira. Sua coleção de obras compreende 6 volumes in 8. $^{\circ}$, grandes. Em 1861 foram publicadas suas Memórias, lamentàvelmente incompletas .

Em 2 de dezembro de 1858 o Sr. D. Pedro II conferiu-lhe o título nobiliárquico de Conde de Santa Ctưz e em 14 de março de 1860 elevou-o a Marquês.

Conde da Conceição - D. Antônio Ferreira Viçoso. Nascido em Peniche (Portugal) em 13 de maio de 1782 e falecido em 7 de julho de 1875 em Mariana (Província de Minas Gerais), era filho de Jacinto Ferreira Viçoso e de Dona Maria Gonçalves Viçosa. Veio de Portugal em 1820, como missionário da Congregação de São Vicente de Paulo, a convite de $D$. João VI, para abrir missões no Mato Grosso.

Apenas, porém, chegado ao Rio de Janeiro, recebeu a incumbência de ir dirigir em Minas Gerais o Colégio do Caraça ali fundado, pela doação do Irmão Lourenço de seu convento ao govêrno real. Esse estabelecimento seria o colégio mais afamado da Província.

Mais tarde foi mandado organizar o Colégio de Jacuecanga e o de Angra dos Reis, que dirigiu até ser nomeado Visitador. Foi o 7. ${ }^{\circ}$ Bispo ide Mariana, diocese criada pela bula Candor Lucis, de S.S. o Papa Benedito XIV, em 6 de dezembro de 1745. A cerimônia de sua sagração foi presidida pelo Bispo do Rio de Janeiro, Conde de Irajá.

Era do Conselho de Sua Majestade e sócio do Instituto Histórico e Geográfico Brasileiro e de várias associações e institutos científicos estrangeiros.

D. Pedro II, atendendo aos relevantes serviços prestados por D. Antônio Viçoso à instrução do Império, condecorou-o com a comenda de Ordem de Cristo e o oficialato da Rosa.

Foi autor de muitas obras e redator de "O Romano". 
Manteve em 1840 longa polêmica ideológica em prol da caùsa do negro desvalido.

Em 7 de março de 1868, agraciou-o o Sr. D. Pedro II com o título nobiliárquico de Conde da Conceição.

Conde de São Salvador -D. Manuel Joaquim da Silveira. Nascido em 11 de abril de 1807, no Rio de Janeiro, e falecido em. 23 de junho de 1875 em São Salvador (Província da Bahia), era filho de Antônio Joaquim da Silveira e de Dona Maria Rosa da Conceição Silveira.

Tendo entrado para o paço como modesto fâmulo, teve, em impresisonante ascenção, carreira eclesiástica das mais brilhantes. e destacadas do $20^{\circ}$ Reinado.

Ordenado presbítero em 2 de maio de 1830 , nove anos depois, no dia dos festejos do décimo quarto aniversário do Imperador, era nomeado cônego da Capela Imperial.

Em 1837 era escolhido para as funções de lente e reitor do Seminário de São José na Bahia.

Em 5 de março de 1843 o Sr. D. Pedro II o designou capelão da divisão naval brasileira, que, sob o comando do chefe de esquadra Teodoro de Beaurepaire iria a Nápoles buscar a Imperatriz do Brasil $D$. Terena Cristina Maria de Bourbon.

Em 20 de outubro de 1844 foi elevado a promotor do Bispado e a seu conselheiro em $10^{\circ}$ de outubro de 1847 .

Em 4 de maio de 1851 era sagrado Bispo do Maranhão e. transferido para a diocese da Bahia em 5 de janeiro de 1868. Logo após, em 19 de março do mesmo ano, era sagrado Arcebispo da Bahia.

Foi cavaleiro da Ordem Real de Francisco I das Duas Sicílias, Comendador da Ordem de Cristo e Oficial da do Cruzeiro. Em 15 de outubro de 1864 celebrou o casamento da Senhora Princesa Imperial Dona Isabel de Bragança com o Marechal do Exér-cito Luís Felipe Maria Fernando Gastão de Orléans, Conde d'Eu.

Escreveu várias cartas pastorais, revelando grande ilustração..

Era do Conselho de Sua Majestade e Grande do Império.

Em 7 de março de 1868 o Sr. D. Pedro II o incorporou à nobreza brasileira, conferindo-lhe o título de Conde de São Salvador.

Marquês do Monte Pascoal - D. Lứs Antônio dos Santos. Nascido em 3 de março de 1817 em Angra dos Reis (Províneia. do Rio de Janeiro) e falecido em 11 de março de 1891 na Capital do Estado da Bahia, era filho de Salvador dos Santos Reis ede Dona Maria Antônia da Conceição Santos.

Fêz seus primerios estudos no Rio de Janeiro e foi ordenado presbítero secular, ao concluir o curso do Seminário de Jacuecanga. 
Pertenceu zo quadro de lentes do Colégio do Caraça, onde regeu a cadeira de Matemática. Foi depois transferido para o Seminário Episcopal de Mariana, onde também lecionou várias matérias. Doutorou-se em Direito Canônico em Roma em 1851. riana.

De volta ao Brasil, continuou em suas antigas funções em $\mathrm{Ma}$ -

Em 1859 foi nomeado Bispo do Ceará, nomeação logo depois confirmada por bula de S.S. o Papa Pio $I X$.

Em 15 de novembro de 1879 foi elevado à alta dignidade de Arcebispo da Bahia e Primaz do Brasil.

Por se terem agravado seus sofrimentos físicos, renunciou a êsses elevados cargos em 1890.

Era do Conselho de Sua Majestade e prelado assistente do Sólio Pontifício.

Em 16 de maio de 1888 a Princesa Imperial Regente $D$. Isabel, Condessa d'Eu, agraciou-o com o título nobiliárquico de $M a r-$ quês do Monte Pascoal.

Conde de Santo Agostinho - D. José Pereira da Silva Barros. Nascido em 24 de novembro de 1835 em Taubaté (Província de São Paulo) e falecido em 16 de abril de 1898 na mesma cidade, era filho do Capitão Jacinto Pereira da Silva e de Dona Ana Joaquina de Alvarenga Barros.

Iniciou seus estudos no Convento de Santa Clara e os concluiu no Seminário Episcopal de São Paulo em 1858, recebendo ordens de presbítero.

Em 1864 foi nomeado Vigário de Taubaté, aí permanecendo durante 19 anos.

Nomeado Bispo de Olinda em 1881, foi a primeira voz do alto clero brasileiro a se erguer a favor da abolição da escravidão negra.

Em 1891 foi removido para a diocese do Rio de Janeiro, onde ficou até ser ela, em 1894, elevada a Arquidiocese.

Nessa ocasião foi preterido pela nomeação para Arcebispo do Rio de Janeiro, de Monsenhor João Fernando Tiago Esberard. Esse fato, que causou enorme pesar, pelas qualidades excepcionais de $D$. José, provocou forte polêmica no Congresso e nas colunas dos jornais.

Nomeado, logo após, Arcebispo titular de Darnis, retirou-se desgostoso para sua cidade natal, onde terminou seus dias praticando o bem e a caridade.

Roi camarista secreto de S.S. o Papa Pio $I X$, conselheiro de Sua Majestade Imperial e Capelão-mor de sua casa, Assistente do Sólio Pontifício e Prelado Doméstico de Sua Santidade. 
Em 16 de maio de 1888 a Regente do Império Dona Isabel de Bragança, Condessa d'Eu, conferiu-lhe o título nobiliárquico deConde de Santo Agostinho.

Conde de Santa Fé - D. Pedro Maria de Lacerda. Nascido em 31 de janeiro de 1830 na Capital do Império, ali faleceu em. 12 de novembro de 1890 e era filho de João Pereira de Lacerda, Capitão de Mar e Guerra, e de Dona Camila Leonot Fontes deLacerda.

Fêz os estudos de humanidades no Rio de Janeiro, de onde. seguiu para Roma, aí doutorando-se em Teologia.

Em 1852 foi ordenado presbítero secular na cidade de Mariana e um mês depois nomeado Cônego da Catedral, cargo a que renunciou em 1860.

Lecionou, desde 1858, filosofia, matemática e línguas no Seminário Episcopal, de onde saiu em 1868 por ter sido nomeado Bispo do Rio de Janeiro.

Assistiu ao Concílio Romano em que foi reconhecida a infalibilidade do Chefe da Igreja. Em 1877 esteve novamente em Ro$\mathrm{ma}$, em peregrinação "ad limina apostolorum".

Teve desassombrada atitude em 4 de março de 1872, ao suspender o prelado fluminense Padre Almeida Martins, em razão deum discurso que fizera na véspera, numa solenidade maçônica, a que presidira o Grão-Mestre da Maçonaria Brasileira e Presidente do Conselho de Ministros, o Visconde do Rio Branco. Atraía para. si, conscientemente, os ódios da poderosa organização secreta, que felizmente teria vida curta, pelo desprêzo que sempre lhe votou nosso segundo Imperador, que nunca pisou em suas lojas ou ao" menos teve curiosidade para assistir ao misterioso ritual.

Era $D$. Pedro Lacerda homem que colocava acima de tudo: seu dever de Príncipe da Igreja.

Dois fatos de sua administração, além do acima lembrado, são dignos de registro: o enérgico protesto junto ao Govêrno Imperial, para que não mais se realizassem no interior das igrejas as eleições políticas e a fundamentada representação contra a prisão, julgamento e condenação do ilustre Bispo de Olinda $D$. Vital Maria Gonçalves de Oliveira.

Em 1888 é êle nomeado Arcebispo da Bahia, mas declina da. honraria.

Figuram entre suas obras de alta benemerência a fundação do Colégio Salesiano de Niterói e a remodelação do de São José..

Era, ainda, Assistente do Sólio Pontifício e Prelado Doméstico de Sua Santidade. 
Esse homem que teve do Império as mais altas e cobiçadas honrarias - Conselheiro de Sua Majestade, seu Capelão-mor, Grande do Império e Comendador das Ordens de Cristo e da Rosa nunca se conformou com o vexame sofrido pela Igreja Católica, que foi a prisão de dois de seus mais dignos prelados.

Conta-nos o saudoso e sábio Dr. Capistrano de Abreu que o nobre antístite atravessava, em 16 de novembro de 1889 , o velho Largo do Paço, quando observou que a cidade estava repleta de soldados e marinheiros. Quando the informaram o que ocorrera na véspera e que o Sr. $D$. Pedro II, com tôda a Família Imperial, era prisioneiro do Govêrno Provisório da República, teve estas palavras cheias de amargor: "Exatamente o que êle fêz com os Bispos!"

E nem a corôa de Conde - que a Senhora Princesa Dona Isabel, Regente do Império - colocara, em 16 de maio de 1888, sôbre suas armas de Príncipe da Igreja, lhe conseguiu conquistar incondicional simpatia.

Prof. ANTÓNIO DA ROCHA ALMEIDA

da Faculdade de Filosofia da Universidade do Rio Grande do Sul. 